\title{
Public heritage and the promise of the digital
}

\author{
Jenny Kidd, School of Journalism, Media and Cultural Studies, Cardiff University
}

\begin{abstract}
The 'promise' of the digital has been a democratization of the notion of heritage, and a disruption of ideas about ownership, authorship and authenticity that might have seemed more straightforward in the recent past. This chapter overviews these possibilities before going on to introduce a series of ethical questions that complicate that picture. It appraises three practices which exemplify this conflicted terrain and demonstrate the issues at stake; heritage institutions' uses of social media, crowd-based methods and immersive mobile encounters.
\end{abstract}

Keywords: digital, ethics, citizen humanities, crowdsourcing, mobile. 
Our encounters with cultural heritage have become increasingly multimodal, collaborative and mediatized. They are also nomadic; shifting online, offline and collapsing the spaces in between. How digital media are impacting our understandings of heritage, and how those understandings in turn intersect with the public realm, are questions of considerable interest. Margarita DíazAndreu asserts that 'the digital revolution has ... affected the way in which the interaction between heritage and the public takes place' (2017: 404-405). It is certainly the case that heritage 'making' is a thing made hyper-visible by digital media, open to constant and continuous negotiation, potentially against a backdrop of global scrutiny.

The 'promise' of the digital has been a democratization of the very notion of heritage, and a disruption of ideas about ownership, authorship and authenticity that might have seemed more straightforward in the recent past. This has consequently raised searching questions about cultural value; how it is ascribed, on what basis, and by whom (Adair et al. 2011). These developments have received significant attention and some scrutiny in scholarly debates (in, for example, Giaccardi 2012, Drotner and Schrøder 2013, Kidd 2014, Ridge 2014). Much has been made of the role of the digital in overturning our long established 'authorised heritage discourse' (Smith 2006), in safeguarding intangible heritages including those in minority languages (Antonaci et al. 2013, Hubin et al. 2013), and in curating previously hidden or marginalized histories (Kidd et al. 2014). 'Open' versus 'closed' heritage practices have also been brought sharply into focus in debates about the affordances of different hardware and software ‘solutions' (Owens, 2016).

Alongside the argument that digital media might democratize cultural heritage is the related assumption that such media might also aid heritage institutions in their ongoing attempts to remain relevant. As Gertraud Koch notes 'cultural heritage can only remain a living part of cultural practice as long as it can incorporate social and technological change and thus remain contemporary' (Koch 2013: 169). There is a seductive logic underpinning claims that young people in particular might respond positively to digital manifestations of heritage, or that reaching them might be only a matter of tapping into the latest social media platform; seeking them out and engaging with them where they already are.

Joel Taylor and Laura Kate Gibson have however identified a 'notable reluctance' to critique digital practices ostensibly designed with democratization in mind (2016: 408). Their own incredibly valuable intervention in the literature explores a disconnect 'between increased access and increased democracy' (2016: 409) which although established within communications studies, does seem to have been overlooked in the heritage discourse. They raise valuable questions about the extent to which digital media in and of themselves can be expected to facilitate more and better democratization of heritage.

Following Barbara J. Little (2009: 30) in her taxonomy of approaches to public archaeology, I would like to suggest that digital heritage intersects with notions of 'the public' in four distinct ways. Firstly, digital heritage work can be funded by the public; for example through state support, the work of research councils, or directly via crowdfunding initiatives. Secondly, such work often happens as part of outreach and education initiatives bringing heritage into commune with communities variously defined; in digital storytelling workshops and through online games 
for example. Thirdly, there is digital heritage work designed to 'solve societal problems', such as that done under the auspices of European Union funded schemes. And lastly, there is the not insignificant work carried out by non-professionals through, for example, citizen science and citizen humanities initiatives. This is then a complex picture, with many and much invested at the points where notions of heritage, the public, and the digital intersect.

This contribution appraises and problematizes the logics which often bolster talk about digital media's potential to radically alter the grounds upon which heritage is (co-)produced and circulated. It will highlight a range of ethical dimensions to those debates, dimensions which are often sidelined or revealed only through close scrutiny at the interstices of heritage studies with other disciplines, such as media and communications studies, or the digital humanities. There has been some attempt to bring this more reflexive agenda to scholarship on heritage and digital media, but it has thus far been somewhat limited (see for example Marstine, 2011, Fouseki \& Vacharopoulou, 2013, Holdgaard \& Klastrup, 2014, Hartley 2015, Pantalony, 2016, Kidd and Cardiff, 2017).

In this chapter I will explore the promises and challenges of three practices currently being positioned as game-changers in the pursuit of a more authentically public conceptualization of heritage. These are: the turn toward social media, crowd-based methods more broadly, and immersive mobile encounters. Although the particular projects and platforms referenced here may well prove to be ephemeral, the questions raised will be with us for some time to come, and the critiques themselves will likely become amplified.

\section{Social media}

Social media communications provide much in the way of promise for a more open and dynamic understanding of heritage, offering scope for dialogue, sharing and playfulness in our negotiation of the past (Kelly 2013, Giaccardi 2012, Parry 2011). Such networks are seen to represent a shift from a broadcast or 'transmission' model of communications by heritage institutions, to a networked communication model, one that is purported to be less hierarchical and exclusionary (Drotner and Schrøder 2013). This has led to great claims about the prospects of social media for more and better public heritage:

Social media starts by offering a way to 'widen the audience', 'reach new constituencies' but it ends by changing heritage and by asking everyone to participate in its construction, encouraging openness not closure of interpretation and valuation, making flux, uncertainty and doubt critical. (Fairclough 2012: xvi-xvii)

Social network sites - for example Facebook, Instagram and Twitter - are no doubt intriguing in light of these claims. Critically, given the interests of this volume, such platforms operate on a basis of openness as a default, privileging the public over the private as core to their business models. They foreground sharing, conversation and debate, lowering barriers to enter into those debates, and offering the potential for impressive reach and a diversity of voices. They also allow users to upload their own content and to respond in real time to real world events and stimuli. All of the time of course, they are also making 'visible the museum's networks of social relations' (Sánchez Laws 2015: 6) in ways that might be institutionally compelling, and which seem to offer 
a rebalancing of power. At face value, the capacity of such platforms to 'change heritage' might seem self-evident.

There are a great number of heritage institutions being recognized for their work within social media spaces ${ }^{1}$, especially noteworthy given the incredible competition for attention that is now a given within such environments, and the sobering assessment of Henry Jenkins et al. that if it doesn't spread it's dead' (2013). The popularity of projects such as Culture 24s VanGoYourself attest to the spreadability of forms of user created content and playful remix. The award winning VanGoYourself platform offers users the opportunity to produce and circulate their own recreations of paintings, including those of the 'masters', with a view to 'get[ting] inside them and discover[ing] art in a whole new way' (Culture24, undated). Sharable content is the holy grail of digital communications and promotions, as evidenced also in the wildly popular \#MuseumSelfie initiative. It is events like the \#AskACurator day held annually in September that we might also look to in order to assess the capacities of social media to open up understandings of and interest in heritage. \#AskACurator has become a global event premised on the idea that digital provides a platform for genuine exchanges between those with different kinds and levels of expertise, both amateur and professional museum and heritage 'makers'.

However research into uses of social media sites within heritage organisations has offered mixed readings of their capacity to enable more and/or better democratic exchanges around, or in the production of, heritage content. I have found in my own research (Kidd 2011, 2014) that uses of social media by museums (for example) are often shallow and dominated by marketing and brand messaging. Taylor and Gibson have found that where interactions do happen in social media spaces, they tend to be focused on pre-selected subject matters which leave little room for people to '[define] their heritage according to their own values' (2016: 10). Ana Luisa Sánchez Laws too has studied participation, sustainability, trust, diversity and questions about representation as they map onto museums' social media presence, and cautions that '[s]ome assumptions about the potential of social media to foster broader public engagement and participation (and to therefore be always beneficial to museums, regardless of their type) need to be examined' (Sánchez Laws 2015: 3).

There has been an assumption that 'the more people can be actively involved in discussion, debate and consensus-building, the more legitimate the insights' (Albert, 2013: 6), yet this idea of legitimacy is a slippery one. Who gets to decide what the measure of legitimacy is? What is the relationship between 'more people' and better insight? And is consensus always practicable and desirable? Vincent Miller (2008: 399) has posited that communication within social network sites tends toward 'phatic' small talk rather than meaningful conversation or debate, and there have been more troubling assessments of the level and tone of discussions in recent years (deemed especially problematic within the Twittersphere (Kidd 2015)).

There are issues too about the kinds of infrastructures and permissions that have become normative within these environments, and questions about platform politics and uses of data that heritage institutions and researchers may not be attuned to. Social design is at the core of

\footnotetext{
${ }^{1}$ See for example those recognized by the annual Museums and the Web GLAMI awards. http://mw2016.museumsandtheweb.com/glami-winners/
} 
these platforms (White et al 2013: 390), but it has its limitations. Perennial problems around access mean that reach within such spaces is multiply skewed, and any understanding of community likely flawed (Baym 2010: 74). In addition, the sharing of content turns networking into cultural capital which largely accrues to heritage institutions rather than individuals, or economic capital which accrues to the owners of the platforms which underpin the projects. Savvy users may be unwilling to enter into interactions on those bases.

When evaluating projects that have involved the use of social media, heritage institutions and organisations need to think about the measures for success that have become normative. Reach is only one measure, assessed by quantitative means, and may of course not be the best one in the final analysis. It says nothing about the depth or quality of interactions from either the user perspective, or that of the institution. Sánchez Laws (2015: 6) proposes that we need to do much more in order 'to understand when, how and why these activities may have a positive, neutral or negative result', for their impacts might be ambiguous at best. This raises also the specter of intentionality and motivation for the programme in the first instance, and how considered and well-articulated that is.

There are then problems with the premise that social media per se are a viable route to more public negotiations of heritage. But what might be said about seemingly more involved direct appeals to 'the crowd' to problem solve with and alongside heritage institutions? 'The next section will explore this thematic in more detail.

\section{Crowd-based methods}

Since the mid 2000s we have witnessed an explosion in rhetoric about the capacities of digital media to leverage the 'wisdom of crowds' (Surowieki, 2004) and to make use of our 'cognitive surplus' (Shirky 2010). The discourse speaks of participation, community and empowerment, and is thus also incredibly seductive for heritage practitioners keen to democratise the stories they work with. Underpinning these developments is an assumption that the involvement of 'citizens' in heritage work will render it in some way more genuinely public, and that the kinds of knowledge produced and circulated as a result will be more representative and authentic. Such outcomes are however never inevitable.

'Crowdsourcing' for example has been defined as 'inviting members of the public, often referred to as "the crowd," to tag and classify, transcribe, organize, and otherwise add value to digital cultural heritage collection content' (Owens 2013: 121). Such approaches are often used as part of citizen science and citizen humanities initiatives about which there is an emerging literature (see for example Dobreva et al. 2014, Carletti et al. 2013, Ridge 2013, 2014). These are projects that - whether situated within University research programmes, or the Education Departments of museums and heritage sites - are touted as opening up knowledge production.

There are many examples of citizen science programmes that could be cited here but I shall briefly focus on the offers from two institutions. The Natural History Museum in London has no fewer than five science projects live as of May 2017 which encourage 'citizens' to get involved in activity varying from exploring the distribution of seaweed around the UK as part of the 'Big 
Seaweed Search', to transcribing microscopic slide labels for the 'Miniature Lives Magnified' initiative. According to the museum these projects 'invite you [the citizen] to actively contribute to our science research' (Natural History Museum, undated), making the data richer, and more comprehensive than is practicable otherwise without major project investment. Similarly, the Australian Museum has no fewer than six current projects, including 'Australian Fishes' which sees 'citizens' uploading and identifying their own observations of marine life, and 'Solarpowered Ibis' which calls upon people to keep their eyes open for birds with wing tags and to email the project if they happen to see any. In terms of citizen humanities projects, there are again many options for people to get involved; on the Smithsonian website people can head to the transcription center to become a 'digital volunteer' (Smithsonian, undated), 'History Unfolded' encourages citizens to work with the United States Holocaust Memorial Museum, searching online local news archives for articles and submitting them to the online database, and 'annoTATE' asks people to help transcribe documents from the Tate collection of artists' diaries and letters.

But there are challenges associated with these approaches also, and as noted above, ethical dimensions that we are only beginning to consider. One of the major concerns with the crowdsourcing approach has been around assessment of the labor involved; why 'outsource' that work to members of your community rather than pay somebody to do it? Is it exploitative? Does it undervalue and even devalue the work involved? Why do people participate in the numbers that they do? What in fact is being traded? There are broader debates about digital labor happening across the disciplines (Terranova 2000, van Dijck 2012, Fuchs and Sevignani 2013, Owens 2013, Fuchs 2014), and the case for how and why heritage crowdsourcing might be considered exempt from those criticisms has yet to be adequately argued.

As with the consideration of social media above, there are also questions about access, sustainability and trust that emerge within this kind of work. Just who is this crowd that heritage organisations are appealing to? And who does it exclude (and it always excludes somebody)? We know that there continue to be inequalities in digital access along the lines of age, geography, ethnicity, disability and education (for example), so how might these be overcome? How we create interfaces that enable and encourage participation in such initiatives is the subject of ongoing exploration, but perhaps not enough reflection. We might also note potential issues around how to manage peoples' expectations of what being involved in a project means, and their sense of what might happen to the associated outputs, including the extent to which their contribution is likely to influence the way that particular subject matter will be worked with and articulated in the future.

\section{Immersive mobile encounters}

Another area of exploration is the increased number of immersive mobile encounters that are available for visitors and users to interact with. As Sánchez Laws notes, there are many heritage organizations 'experimenting with hybrid physical-digital combinations enabled by mobile technologies', a fact that demonstrates that the 'shape of online narratives continues to evolve' (Sánchez Laws 2015: 2). There are of course a multitude of mobile applications (apps) which serve a wayfinding and interpretive function on site at museums and heritage sites, and those 
have been the subject of quite some reflection in the literature (Lagoudi and Sexton 2010, Cromartie 2012, Robson et al. 2016), but here I wish to focus on more intriguing and (perhaps) ambiguous apps that encourage atypical interactions between members of the public and the heritages on offer.

One emergent format for such encounters is the 'subtle mob', which has been trialled by both the Museum of London ('A Hollow Body') and Amgueddfa Cymru - National Museum Wales ('Traces'/'Olion') in recent years. Whereas flash mobs are noisy, hyper-visible interventions in public spaces, subtle mobs are quite the opposite. They are quieter, slower, more considered, and invisible to the onlooker. They are designed to make participants respond to and view their environments, or the 'stage', in new ways, and they are expressly performative.

'Traces' for example ('Olion' in the Welsh language version) is an attempt to create a digital heritage encounter via a mobile application that changes peoples' relationship with the space of the St Fagans National History Museum. Rather than a faithful interpretation of the site which might overlay the existing interpretation, the experience is conceived instead as an artistic narrative composition inspired by the site. 'Traces' was created in partnership with a street gaming company, and is designed to be game-like, story-like and interpretation-lite. But this raises questions also about the ways in which 'truth' and 'fact' might be being negotiated, and to what extent their disruption might be consequential. At a time when heritage institutions are trusted by the general public (in the global north at least) more than media or government sources, is it the right time to foreground playfulness, or to engender a more questioning and critical approach in citizens toward the truth-claims that such institutions have made and continue to make?

Other formats raise fewer such questions, and are notable in their attempts to offer a plurality of perspectives that might otherwise be missing from a heritage encounter. The Holocaust Memorial mobile app for Miami Beach, the 9/11 Memorial Guide app, or the Slavery at Monticello app for example all allow access to stories in different voices. The last of these, Slavery at Monticello, is an app created by the Thomas Jefferson Foundation for use at the Monticello World Heritage Site, a former plantation and home to the Jefferson family. The app introduces stories of slavery through multiple perspectives and promises that 'Once you hear their stories you will never forget them ... this app presents a small piece of their story'. The app presents mixed-media insights into 17 peoples' stories, including those of James Hubbard 'A Runaway' slave, Sally Hemings 'Domestic Servant and Devoted Mother', and Thomas Jefferson 'American President, Slave Owner'. The app seeks to present an insight into 'The Messiness of History' via a rich and immersive mediascape that people can navigate on their own terms.

Such projects produce or curate what might be termed 'multimodal' digital heritage encounters; they utilise multiple modalities including sounds, smells, gestures, but also spatial resources and other inputs from the environment. Sarah Kenderdine has noted the multimodal 'real' in her analysis of embodiment in digital heritage encounters: 'embodiment is multisensory and results from effects of visual, auditory, tactile, olfactory, and gustatory cues. Embodiment is entanglement through, and with, context and environment' (2016, 29, see also Hanna Schraffenberger and Edwin van der Heide). These approaches demonstrate institutions starting to think more carefully and creatively about how they can encourage symbiosis between space 
and content, interactions which enable new kinds of experience or knowledge to emerge, and which implicate the user in the experience. They show an understanding of the environment as a 'sense-scape' (Young 2007 in Kenderdine 2016), an accumulation of unique spatial and historical elements that can themselves be significant resources. They work beyond traditional conceptions of 'visitor' and 'visiting' which have been exploded in recent years, and they seek to embrace increased fluidity between digital and physical, online and offline, hoping to create frictionless hybrid encounters.

But there are challenges here also, and a re-emergence of questions about accessibility, usability and platform politics. Sustainability is also a concern, especially given the not insignificant amounts of money set aside for such initiatives. The ongoing frustration with mobile applications is of course getting people to download them in the first instance, and they can be fiendishly difficult things to evaluate also. Indeed, evaluating digital heritage projects generally is often an area of quite considerable unease for those who are involved at the sharp end of project delivery and reporting.

\section{Conclusion}

The above attests to the creativity and excitement that is a facet of our current explorations in using digital for the benefit of public heritage variously defined. What it also demonstrates however is the need for reflexivity and care as key components of professional practice in this area. If those fail there is a real risk that the very public $[\mathrm{s}]$ heritage institutions actively court within the digital mediascape will be misunderstood and (ultimately) ill-served. There is a tendency to see the digital as a way of opening up access, democratizing heritage and broadening its scope, but these things are never inevitable, and need to be subject to honest and repeated appraisal. Taylor and Gibson diagnose this problem acutely when they note that:

[m]obilising people to engage with heritage is valuable and interesting, but the role of digitisation and social media in the democratisation of heritage needs to be better understood. Understanding the implications, particularly unintended, that come from digitising or digital engagement becomes increasingly important (Taylor \& Gibson 2016: 417).

Their reference here to unintended implications is a reminder that heritage organisations need to gain a better grasp of questions around platform politics, privacy, data misuse and how all of these things intersect with questions about power. As Pickover has said, 'digitisation and digital interaction with heritage today cannot be seen as a 'neutral' activity divorced from the entangled power relations of our past' (Pickover 2014 in Taylor \& Gibson 2016: 409).

Elsewhere I have argued that recognizing these issues is akin to a new professional literacy for those who work in, through and with digital heritage (Kidd 2018). This needs to involve scrutiny of practice along a number of evaluative criteria; Why digital public heritage? Which public(s) are represented? Whose measures of success are being privileged and what do they amount to '? How have choices about formats, platforms, framing, moderation and institutional voice impacted the kinds of engagement and/or 'democracy' that are possible? Only close and 
considered reflexivity with those publics, and perhaps also with those who are excluded, will offer insight into whether the promises of digital public heritage have been achieved, or are achievable. We do our communities no service at all if we skate over these issues, and are instead in danger of replicating the problematics of past heritage practices that the very process of becoming digital was supposed to overturn.

\section{Bibliography}

Adair, Bill, Filene, Benjamin, and Koloski, Laura, (2011), Letting Go? Sharing Historical Authority in a User-generated World, Philadelphia: The Pew Center for Arts and Heritage.

Albert, Marie-Theres, 2013, 'Introduction' in Marie Theres Albert, Roland Bernecker and Britta Rudolff (eds), Understanding Heritage. Berlin, Boston: DE Gruyter. Pp.169-181

Antonaci, Alessandra, Bravi, Paolo, Dagnino, Lutzu, Marco, Francesca Maria, Ott, Michela, Pilosu, Sebastiano and Pozzi, Francesca, 2013, 'Digital technology and transmission of Intangible Cultural Heritage: the case of Cantu a Tenore' in 2013 Digital heritage International Congress proceedings Pg. 11

Baym, Nancy K. 2010. Personal Connection in the Digital Age. Cambridge and MA: Polity Press.

Carletti, L, McAuley, D, Price, D, Giannachi, G, and Benford, S. 2013. 'Digital Humanities and Crowdsourcing: An Exploration' In Museums and the Web 2013, N. Proctor \& R. Cherry (eds). Silver Spring, MD: Museums and the Web.

Cromartie, Nicole, 2012, 'ArtClix Mobile App at the High Museum of Art' available at http://www.museumsandtheweb.com/mw2012/papers/artclix mobile app at the high muse um of art.html [Accessed 19th May 2017]

Culture24, undated, 'About VanGoYourself available at http://vangoyourself.com/about/ [Accessed 18 ${ }^{\text {th }}$ May 2017].

Díaz-Andreu, Margarita, 2017, 'Introduction to the themed section 'digital heritage and the public' in International Journal of Heritage Studies 23(5) pp.404-407.

Dobreva, Milena, \& Azzopardi, Daniela. 2014. 'Citizen Science in the Humanities: A promise for creativity' in Papadopoulos, G.A. (ed.) 2014. Cyprus Library The 9th International Conference on Knowledge, Information and Creativity Support Systems, University of Cyprus, Nicosia, Cyprus. Available at

https://www.um.edu.mt/library/oar/bitstream/handle/123456789/987/KICSS2014\%20dobre va azzopardi.pdf?sequence $=1$ \&isAllowed $=\mathrm{y}$ [Accessed 21 $1^{\text {st }}$ April 2017]

Drotner, Kirsten, and Schrøder, Kim Christian, (2013), Museum Communication and Social Media: The Connected Museum, New York and London: Routledge 
Fouseki, K., and Vacharopoulou, K. (2013). 'Digital Museum Collections and Social Media: Ethical Considerations of Ownership and Use' in the Journal of Conservation and Museum Studies available at http://www.jcms-journal.com/collections/special/museum-ethics/ [Accessed July 26, 2016]

Fuchs, Christian. 2014. Social Media: A Critical Introduction. London: Sage.

Fuchs, Christian and Sevignani, Sebastian. 2013. 'What is Digital Labour? What is Digital Work? What's their Difference? And why do these Questions Matter for Understanding Social Media?' in tripleC 11(2) 237-293.

Giaccardi, Elisa, (ed) (2012), Heritage and Social Media, London and New York: Routledge.

Hartley, Julian A. 'Museums and the Digital Public Space: Researching digital engagement practice at the Whitworth Art Gallery' unpublished doctoral thesis available at https://www.research.manchester.ac.uk/portal/en/theses/museums-and-the-digital-publicspace-researching-digital-engagement-practiceat-the-whitworth-art-gallery(8eebb8f4-b0b5-4e40a419-50be3c2e6e9a).html [Accessed $18^{\text {th }}$ May 2017]

Holdgaard, Nanna \& Klastrup, Lisbeth, 2014 'Between control and creativity: challenging cocreation and social media use in a museum context' in Digital Creativity 25(3). Pp. 190-202.

Hubin, Yin, Qubumo, Bamo, Cuixiao, Guo, Gane, Li, 2013 'Achive/Base/Network: A threefold solution for safeguarding ethnic minorities' oral heritage in China' in 2013 Digital Heritage International Congress proceedings Pp. 177-180.

Jenkins, henry, Ford, Sam and Green, Joshua, 2013, Spreadable Media: Creating value and meaning in a networked culture. New York \& London: NYU Press.

Kenderdine, Sarah. 2016. "Embodiment, Entanglement, and Immersion in Digital Cultural Heritage." In A New Companion to Digital Humanities, edited by Susan Schreibman, Ray Siemens, and John Unsworth, 22-41?. Chichester and Malden?: John Wiley and Sons Ltd.

Kidd, Jenny. 2014. Museums in the New Mediascape: Transmedia, Participation, Ethics. Routledge.

Kidd, Jenny, 2015, Representation: Key Ideas in Media and Culture. London and New York: Routledge.

Kidd, Jenny and Cardiff, Rosie. 2017. "A space of negotiation": visitor generated content and ethics at Tate'. Museum and Society 15(1), pp. 43-55.

Koch, Gertraud, 2013, 'Studying Heritage in the Digital Era' in Marie Theres Albert, Roland Bernecker and Britta Rudolff (ed), Understanding Heritage. Berlin, Boston: DE Gruyter. Pp.169181.

Lagoudi, Elena and Sexton, Charlotte, 2010, 'Old Masters at Your Fingertips: the Journey of Creating a Museum App for the iPhone \& iTouch' available at 
http://www.museumsandtheweb.com/mw2010/papers/lagoudi/lagoudi.html [Accessed 19th May 2017]

Little, Barbara J. 2009. 'Public archaeology in the United States in the early twentieth century' in Marie Louise Stig Sørensen and John Carman (eds) Heritage Studies: Methods and Approaches. London \& New York: Routledge. Pp. 29-51.

Marstine, Janet (ed) (2011) Routledge Companion to Museum Ethics: Redefining Ethics for the Twenty-First Century Museum, London and New York: Routledge.

Miller, Vincent, 2008, 'New Media, Networking, and Phatic Culture', Convergence 14(4) pp/387 400 .

Natural History Museum, undated, 'Citizen science' available at http://www.nhm.ac.uk/takepart/citizen-science.html [Accessed 18th May 2017]

Owens, Trevor, 2013, 'Digital Cultural heritage and the Crowd' in Curator: The Museum Journal 56(1) pp. 121-130.

Owens, Trevor, 2016, 'Curating in the Open: A Case for Iteratively and Openly Publishing Curatorial Research on the Web' in Curator: The Museums Journal 59(4) pp. 427-442.

Pantalony, R. E. (2016). 'Dances with Intellectual Property: Museums, monetization and digitization' in Murphy, Bernice L. 2016, Museums, Ethics and Cultural Heritage (pp. 71-78). New York and Oxon: Routledge.

Ridge, Mia. 2013. 'From tagging to theorizing: deepening engagement with cultural heritage through crowdsourcing' in Curator: The Museum Journal 56(4) pp.435-450.

Ridge, Mia, (ed) (2014), Crowdsourcing Our Cultural Heritage, Surrey: Ashgate.

Robson, Tricia, Castro, Gary, Paddon, Mark and Beaman, Alexa, 2016, 'The de Young Museum App by Guidekick as a model for collaborative development, technological innovation, and visitor behavior insight' available at http://mw2016.museumsandtheweb.com/paper/the-deyoung-museum-app-by-guidekick-as-a-model-for-collaborative-development-technologicalinnovation-and-visitor-behavior-insight/ [Accessed $19^{\text {th }}$ May 2017]

Sánchez Laws, Ana Louisa, 2015, Museum Websites and Social Media: Issues of Participation, Sustainability, Trust and Diversity. Berghahn Books.

Schraffenberger, Hanna and Edwin van der Heide. 2014. "Everything Augmented: On the Real in Augmented Reality." CITAR Journal 6 (1): 1729.

Shirky, Clay, 2010, Cognitive Surplus: Creativity and Generosity in a Connected Age. London, New York and Toronto: Penguin. 
Smithsonian, undated, 'Smithsonian Digital Volunteers: Transcription Centre' available at https://transcription.si.edu/ [Accessed 18 ${ }^{\text {th }}$ May 2017]

Surowieki, James, 2004, the Wisdom of Crowds: Why the Many Are Smarter Than the Few. London: Little, Brown.

Taylor, Joel and Gibson, Laura Kate, 2017, 'Digitisation, digital interaction and social media: embedded barriers to democratic heritage' in International Journal of Heritage Studies 23(5) pp. 408420.

Terranova, T 2000 'Free labor: Producing culture for the digital economy' in Social Text 18(2): 3358.

van Dijck, J. 2012 'Facebook as a tool for producing sociality and connectivity' in Television and New Media 13(2) pp. 160-176.

White, Martin, Patoli, Zeeshan, Pascu, Tudor, 2013, 'Knowledge Networking through Social Media for a Digital Heritage Resource' in 2013 Digital Heritage International Congress proceedings Pp. 389 - 392. 